\title{
A INTERAÇÃO DAS CULTURAS BANTU E PORTUGUESA NUMA TIRINHA MOÇAMBICANA
}

\section{NANCY APARECIDA ARAKAKI}

Pós-doutoranda em Linguística Aplicada pela Universidade A POLITÉCNICA, Maputo, Moçambique. Pós-doutoranda em Letras pela Universidade Presbiteriana Mackenzie (UPM), São Paulo, SP, Brasil. E-mail: nancy.arakaki@terra.com.br

\section{VICTOR MATHEUS DA COSTA}

Doutorando em Letras pela Universidade Presbiteriana Mackenzie (UPM), São Paulo, SP, Brasil.

E-mail: vic.tor.ino@hotmail.com

\section{Resumo}

Este artigo pretende demonstrar como se dá a construção de sentido no gênero tirinha a partir da concepção de que texto é um evento comunicativo em que locutor-texto-interlocutor interagem a partir de seus conhecimentos sociocognitivos armazenados na memória de longo termo. Para tanto, apoiamo-nos na teoria da Linguística Textual mais precisamente nas discussões apresentadas por Koch e Elias (2006), Cavalcante (2012) e Marcuschi (2005) para analisar a tirinha, fazendo comentários a respeito do contexto cultural moçambicano.

\section{Palavras-chave}

Linguística textual. Tirinha. Lusofonia. 


\section{INTRODUÇÃO}

Este artigo surgiu do desafio apresentado pelos atuais estudos de Linguística Textual quanto à elaboração de uma proposta pedagógica de ensino da língua por meio do conceito relativo à construção de sentido de texto. Embasados na concepção de que o texto é um evento comunicativo em que locutor-texto-interlocutor interagem para a construção de sentido, recordamo-nos da situação sociocultural e linguística de Moçambique onde a língua portuguesa e as línguas bantu são os meios de comunicação nacional. Propusemo-nos, então, a demonstrar que o gênero tirinha circula cumprindo a função social de preservar e de divulgar a cultura bantu, bem como revela a construção identitária do povo moçambicano a qual é o resultado do processo de aculturação, pois está mesclada com a cultura portuguesa.

Assim, entendemos que a contribuição dos conceitos sociocognitivos ativados no momento da leitura podem colaborar para a reflexão acerca da transposição didática do gênero tirinha para seu uso em sala de aula. Decorrente deste objetivo, guiamos nossa reflexão a partir da afirmação de Koch e Elias (apud CAVALCANTE, 2012, p. 20), em que o texto escrito fundamenta-se numa concepção sociocognitiva interacional de língua, que privilegia os sujeitos e seus conhecimentos em processos de interação.

É dessa forma que o locutor estrutura e organiza o seu texto tendo em mente um interlocutor virtual cujo saber é, em parte, compartilhado. Apoiamos também nossa reflexão no fato de que os gêneros são dinâmicos e devem ser vistos na relação com os interesses sociais, as relações de poder, as atividades discursivas no interior da cultura. Eles são formações interativas, multimodalizadas e flexíveis de organização social e de produção de sentidos (MARCUSCHI, 2005, p. 19).

Para atingir nosso objetivo, organizamos este artigo contemplando a descrição linguística de Moçambique e a análise de uma tirinha que veicula no país no livro Ri amor, de Sergio Zimba.

\section{APRESENTAÇÃO DE MOÇAMBIQUE}

Moçambique é um país multilíngue e multicultural. Para além da língua portuguesa, língua oficial, a grande maioria das línguas faladas em Moçambi- 
que pertence ao grupo bantu. Estas línguas exógenas constituem o principal estrato linguístico tanto com respeito ao número de falantes como em termos da distribuição das línguas pelo território. O mapa linguístico de Moçambique contempla 20 línguas bantu faladas no país o que revela alta diversidade linguística. A língua emakhuwa é a que apresenta número maior de falantes correspondendo a $25 \%$ da população nacional. Dado esse fato, Moçambique apresenta um mosaico linguístico, pois, de acordo com Robinson (apud LOPES, 2004, p. 24), a noção de elevada diversidade linguística se dá no "caso em que uma percentagem não superior a $50 \%$ da população fala a mesma língua”. Em virtude dessa diversidade linguística, a Frente de Libertação de Moçambique (FRELIMO), o partido do governo, optou pela língua portuguesa como língua oficial à época da independência sociopolítica e econômica de Portugal em 1975. Embora a língua portuguesa seja a língua da administração, ela é falada e conhecida por menos de $50 \%$ da população nacional.

É na capital do país - Maputo - que a língua portuguesa revela maior número de falantes, no entanto, a população local faz uso de uma das línguas bantu: changana e/ou ronga. É comum em Maputo constatarmos a população comunicando-se com seus pares em uma dessas línguas nativas. Nesse contexto multilíngue e multicultural, dominar a língua portuguesa é marca de pertença à elite, cujos cidadãos gozam de vários prestígios sociais, principalmente, o de ocupar os cargos mais elevados na hierarquia governamental além de manter laços com o estrangeiro.

No meio rural, $78 \%$ da população não conhece a língua portuguesa. Nesse espaço, predomina a língua bantu regional, embora nos últimos anos o governo esteja investindo no ensino bilíngue. Apenas para maior visibilidade do mosaico linguístico moçambicano, as línguas faladas no campo correspondem cada uma delas ao grupo étnico a que pertence o falante: emakhuwa, cisena, elomwe, ciyanja, cicopi, shimakonde, gitonga, ekoti, kimwani, kiswahili, cisenga, zulu, dentre outras (LOPES, 2004).

O uso efetivo da língua bantu no país nos revela a disposição e o desejo de não se perder a cultura moçambicana, isto porque a história de Moçambique traz as mágoas da época colonial, quando as línguas bantu eram consideradas "línguas de cães" cujos falantes eram vistos socialmente como selvagens.

A partir desse contexto socio-histórico-cultural, defendemos a ideia de que o gênero tirinha colabora para a preservação e divulgação dos costumes e das línguas bantu, pois a língua é o depositário do patrimônio cultural da humanidade. 


\section{GÊNERO TIRINHA E A CONSTRUÇÃO DE SENTIDO INTERACIONAL DAS CULTURAS BANTU E PORTUGUESA}

O humor é a característica típica do gênero tirinha (RAMOS, 2007), no entanto, em Moçambique, ele permite manter a tradição oral dos usos e costumes bantu. Sendo assim, os elementos selecionados pelo locutor permitem a interação entre o leitor moçambicano, além de estabelecer um convite ao leitor não moçambicano.

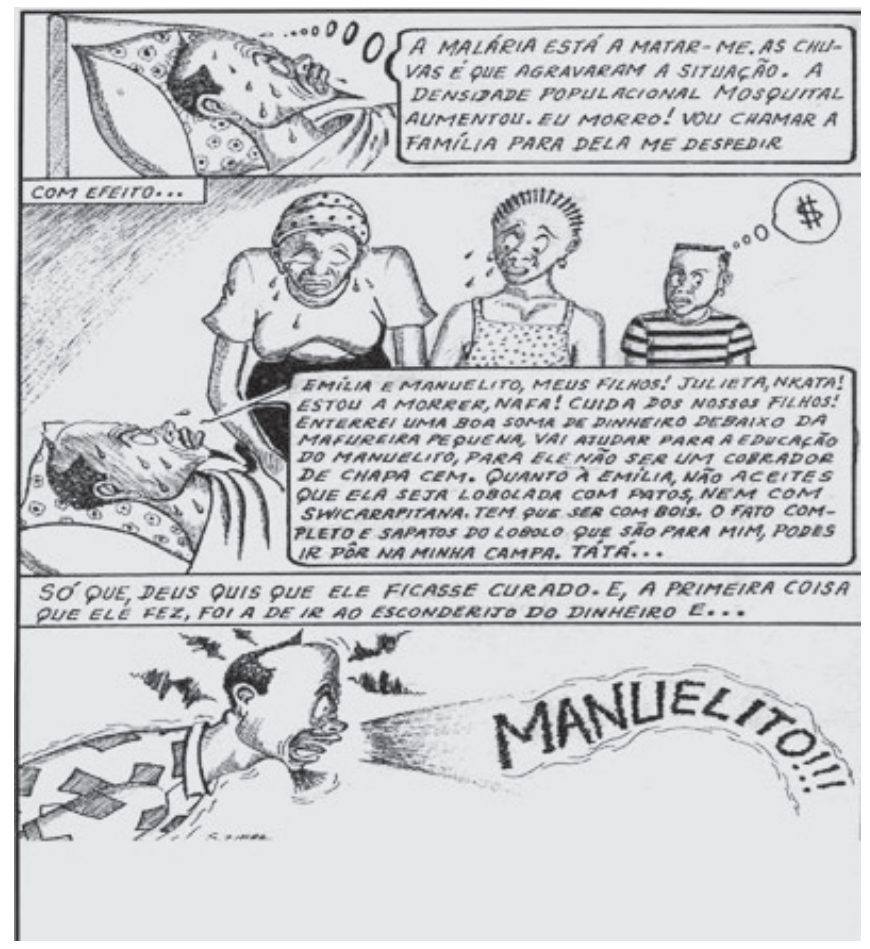

Fonte: Zimba, 2005, p. 29.

O texto acima caracteriza-se como gênero tirinha e defendemos que a intenção comunicativa do autor é a de preservar e divulgar a cultura bantu, que sofreu modificação dado o processo de aculturação com o povo português. A tirinha reúne os elementos que servem de construção textual: a linguagem verbal e a linguagem não verbal, que conjuntamente nos remetem à construção de sentido a partir da concepção de texto como evento comunicativo. Com esse pano de fundo, o gênero em estudo está dotado de recursos colabo- 
rativos para atuação em sala de aula, visto que quando o professor ensina o aluno a operar com um gênero, ensina simultaneamente o modo de atuação sociodiscursiva numa cultura e não um simples modo de produção textual (MARCUSCHI, 2005, p. 19).

O conteúdo temático da tirinha em estudo está organizado pela sequência narrativa e pela sequência injuntiva que passamos a descrever. A sequência narrativa tem como principal objetivo manter a atenção do leitor/ouvinte. Ouvir histórias nos conduz à tradição do povo bantu que é a transmissão oral dos valores e da cultura. A história narrada na tirinha selecionada para análise é a de um pai em seu leito de enfermidade que procura reunir a família em torno de si a fim de passar orientações que lhes garantam a sobrevivência - o dinheiro escondido - ato semelhante à prescrição de um testamento. Entretanto, a história quebra a expectativa do leitor/ouvinte, pois o pai recupera a saúde e vai até o esconderijo do dinheiro. Perplexo por não encontrá-lo, emite um juízo de "furto" pelo próprio filho.

Mediante a síntese da história, esboçamos nossa reflexão a partir da noção que compreende o texto como "um evento comunicativo em que convergem ações linguísticas, culturais, sociais e cognitivas" (CAVALCANTE, 2012, p. 18). Nesse momento da leitura interativa, são consideradas as estratégias sociocognitivas para construção de sentido, quais sejam: o conhecimento linguístico, o conhecimento enciclopédico e o conhecimento interacional.

Para atender à estratégia organizacional, o autor constrói a história por meio do português falado em Moçambique, o qual reúne em seu léxico termos de origem bantu, os quais revelam e, por conseguinte, mantém a cultura bantu. Visto por esse ângulo, é possível reconhecer que a língua revela a interação das culturas portuguesa e bantu no território moçambicano.

A presença da cultura portuguesa na cultura bantu é demonstrada pela criteriosa seleção dos nomes próprios dos personagens: Julieta - a mãe, Emília - a filha, e Manuelito - o filho. A presença da cultura bantu é revelada pela seleção das interjeições bantu: nkata e nafa e pelo substantivo swicarapitana. A interação cultural se dá pela presença do substantivo mafureira, que é uma palavra bantu aportuguesada na sua grafia e pronúncia. As palavras que designam a flora moçambicana se mantiveram devido à riqueza natural do país e por não haver correspondente no português europeu. Mafureira é uma árvore de 10 a 15 metros de altura que se encontra em abundância a sul do Save. A sua madeira é leve, macia e boa para esculpir e executar trabalhos de marcena- 
ria. O fruto da mafureira (mafura) é uma semente que produz óleo comestível e é bom para a fabricação de sabão (LOPES, 2002, p. 89).

Implicitamente, reconhecemos que o pai é marceneiro cuja profissão é concebida como inferior na escala hierárquica. Essa inferioridade do homem bantu frente ao homem português (ex-colonizador) pode ser reconhecida no discurso do pai quando manifesta seu desejo de proporcionar ao filho ascensão social por meio de formação acadêmica: "vai ajudar na educação do Manuelito, para ele não ser um cobrador de chapa cem”. É esse um dos momentos em que o leitor/ouvinte ativa seus conhecimentos enciclopédicos para compreender e dar sentido ao texto produzido. Para o leitor/ouvinte moçambicano, a compreensão é fácil porque esse conhece a cultura local, no entanto, para o leitor/ouvinte não moçambicano a compreensão não se realiza caso ele deixe de investigar o significado de "cobrador de chapa cem". Em Moçambique, "cobrador de chapa cem" é o equivalente em português brasileiro a "cobrador de ônibus; cobrador de vans". Em síntese, "cobrador de chapa cem" significa rapaz que trabalha nas vans de transporte coletivo que circulam pelas ruas da cidade; significa também o preço da passagem: cem meticais, sendo metical o nome da moeda moçambicana, e cem o equivalente a aproximadamente $\mathrm{R} \$ 6,00$ (seis reais).

A interação das culturas bantu e portuguesa é reconhecida pelo termo lobolada, originada de lobolo (termo bantu que significa o dote que o noivo entrega à família da noiva) acrescida do sufixo português "ada". Notamos também a forte presença da cultura portuguesa expressa no emprego de "fato" (o fato completo e sapatos do lobolo) que tanto em Portugal quanto em Moçambique trata-se do equivalente no Brasil a terno (conjunto masculino de paletó e calças).

A tirinha aborda tanto a educação tradicional bantu quanto a educação europeia, pois, assim como em alguns países, a educação em Moçambique é mostra de ascensão social, porém, neste significa dominar a língua portuguesa, ter costumes e hábitos europeus ou mais precisamente luso-bantófonos e pertencer à elite dominante que detém o poder e maior recurso econômico uma vez que esses cidadãos ocupam as melhores ofertas de empregos e, sobretudo, guardar os costumes de ética e de moral. Ressaltamos que a mão de obra moçambicana para o trabalho de menor remuneração principalmente nas cidades exige o conhecimento ainda que rudimentar do Português. Esse contexto socio-cultural contribui para a preservação e uso contínuo das línguas nacionais bantu e vai 
marcando, mesmo que indelevelmente, a cultura e a identidade moçambicana cujos traços denunciam a interação cultural e linguística com a língua e a cultura portuguesa. Enfim, é “a educação que mantém viva a memória de um povo e dá condições para a sua sobrevivência.” (ARANHA, 1989, p. 11).

Retomando o contexto da tirinha, a recuperação da saúde do pai trata-se da quebra de expectativa para o leitor/ouvinte - marca típica das tiras de humor. Note-se que, no primeiro quadrinho, o leitor é informado de que o pai está acometido da terrível malária em consequência das chuvas que inundaram a cidade e, consequentemente, provocaram o aumento da "densidade populacional mosquital”. Isto é, as chuvas trouxeram a epidemia devido à proliferação do mosquito com o aumento de vítimas da malária.

O leitor/ouvinte reconhece tal situação a partir dos elementos utilizados para construção do sentido: a imagem do pai de boca aberta, os traços de indignação desenhados em seu rosto e a grafia do nome Manuelito em caixa alta.

Se, de um lado, verificamos que a sequência narrativa colaborou para a construção de sentido do texto permitindo-nos (re)construir a identidade moçambicana, por outro lado, a sequência injuntiva nos revela a preservação dos costumes bantu e aponta para o futuro: o ensino às gerações futuras. Dentre os bantu, os filhos devem obediência extrema aos pais e não questionam suas decisões. Embora o pai reúna a família - esposa e filhos - seu discurso orientador é direcionado para a mãe. Tal fato nos aponta para o costume bantu em que os filhos devem permanecer calados diante dos pais, bem como diante dos adultos. Tal costume é levado para a escola o que dificulta em grande medida a atuação pedagógica do professor, pois quando este chama um aluno para responder a qualquer questão didática da aula, esse último se levanta, mas permanece calado, tendo em mente estar agindo conforme a educação bantu transmitida pela família.

Notamos, por isso, o emprego das formas verbais no imperativo: "cuida dos nossos filhos; não aceites; podes ir pôr" e a imagem dos filhos em pé à beira da cama do pai enfermo. Verificamos também a denúncia da corrupção no seio familiar por meio da construção do símbolo \$ (cifrão) no balãozinho sobre a cabeça de Manuelito, numa clara evidência de planejar apropriar-se das economias do pai. A corrupção não é inerente à cultura bantu, visto que o homem bantu pensa e age visando o bem coletivo. Esse traço constitutivo do texto também nos permite assegurar que, para o homem bantu, a corrupção é um dos atos advindos da cultura portuguesa. 
Ainda, sob a perspectiva de que texto é um evento comunicativo que exige ativar conhecimentos armazenados na memória, verificamos que a leitura realizada por um leitor não moçambicano fica comprometida, uma vez que o mesmo não tem na sua memória de longo termo o conceito de swicarapitana.

\section{CONSIDERAÇÕES FINAIS}

O gênero tirinha no contexto sociocultural e linguístico de Moçambique serve ao objetivo de tanto ensinar como de propiciar o ensino de língua e cultura por meio de padrões mentais (sociocognitivos) que ressaltam a história e as culturas bantu, portuguesa e luso-bantófona no âmbito dos conhecimentos linguístico, enciclopédico e interacional. Para tanto, basta atentarmos à causa de enfermidade do pai que é a malária, mal que atinge e leva um significativo número de moçambicanos à morte. Ao mesmo tempo em que ensina, divulga $\mathrm{e}$ preconiza a conservação da cultura bantu, a tirinha serve como grande e forte aliado do professor na sua interação em sala de aula, pois “falar não é atualizar um código gramatical num vazio, mas moldar o dizer às formas de um gênero no interior de uma atividade" (Marcuschi, 2005, p. 23).

A rigor, o gênero tirinha, em Moçambique, propicia um momento agradável de interação - professor e aluno - face sua característica principal ser o humor. Visto por esse ângulo, trata-se de um ensino moldado pelo cruzamento de vários discursos que permitem ao aluno conhecer a história de seus ancestrais e a história do país quando governado e explorado pelos portugueses. Assim, um aspecto importante e fundamental desse recurso didático é contribuir para que o espaço sala de aula seja um espaço de construção de sentidos sócio-históricos e culturais, o qual conduz à reflexão e à formação de cidadãos verdadeiramente conscientes de seu papel e de sua função social nesse universo identitário bantu e português.

\section{The interaction of bantu and portuguese cultures in a mozambican comic}

\section{Abstract}

This paper aims to demonstrate how the construction of meaning in the comic genre is given, spawning from the conception of text as a communicative event in 
which locator-text-interlocutor interact using their sociocognitive knowledge stored in the long term memory. For that, we foloow the Text Linguistics and the discussions brought by Koch e Elias (2006); Cavalcante (2012) and Marcuschi (2005). To analyze the comic, commenting about the Mozambican cultural context. In order to meet the description of the Bantu Mozambican cultural space, we rely on the discussions of Arakaki (2014) and, for the precepts of Lusophone Studies, we use the concepts discussed by Brito, Bastos and Bridi (2016), ensuring that Lusophone is a symbolic space to which a cultural and identity diversity converge whose common denominator is the Portuguese Language in its varieties (BASTOS and BRITO, 2006, p.114).

\section{Keywords}

Textual Linguistics. Comics. Lusophone.

\section{REFERÊNCIAS}

CAVAlCANTE, M.M. Os sentidos do texto. São Paulo: Contexto, 2012.

KOCH, I. V.; ELIAS, V. M. Ler e compreender: os sentidos do texto. São Paulo: Contexto, 2006.

LOPES, A. J. Moçambicanismos para um léxico de usos do Português Moçambicano. Maputo: Livraria Universitária, 2002.

LOPES, A. J. A batalha das linguas. Maputo: Imprensa Universitária, 2004.

MARCUSCHI, L. A. Gêneros textuais: configuração, dinamicidade e circulação. In: KARWOSKI, A. M.; GAYDECZKA, B.; BRITO, K.S. (Orgs.). Gêneros textuais: reflexões e ensino. Palmas e União da Vitoria, PR: Kaygangue, 2005.

RAMOS, P. E. Tiras cômicas e piadas: duas leituras, um efeito de humor. Tese (Doutorado em Filologia e Língua Portuguesa). Faculdade de Filosofia, Letras e Ciências Humanas, Universidade de São Paulo, São Paulo, 2007. Disponível em: <http://www.teses.usp. br/teses/disponiveis/8/8142/tde-04092007-141941/>. Acesso em: 4 mar. 2016.

ZIMBA, S. Ri amor. Maputo: Diname, 2005. 